\title{
Anticipating employment location patterns in economic regions: modeling complex dynamics
}

\author{
Sanda Kaufman ${ }^{1 *}$ D, Miron Kaufman ${ }^{2}$ and Mark Salling ${ }^{3}$
}

\author{
* Correspondence: s.kaufman@ \\ csuohio.edu \\ ${ }^{1}$ Department of Urban Studies, \\ Levin College of Urban Affairs, \\ Cleveland State University, 2121 \\ Euclid Avenue, Cleveland, $\mathrm{OH}$ \\ 44115, USA \\ Full list of author information is \\ available at the end of the article
}

\begin{abstract}
Complex social-ecological systems-such as cities and regions-change in time whether or not we intervene through plans and policies. This is due in part to the numerous individual and organizational actors who make self-interested, unilateral decisions. Public decision makers are expected to act in the public interest and are accountable to constituents. They need the ability to explore alternatives, select ones that are likely to benefit the public, and avoid or mitigate negative outcomes. Predicting processes and outcomes in the context of complex systems is risky, however, and mistakes can be costly. Switching from prediction of specific future states to anticipation of possible ranges of futures may help contend with the uncertainties inherent in these systems. We propose here a dynamic network model for generating ranges of possible futures for employment location in an economic region. The model can be used to anticipate employment location effects of various policies. First, using historical (2002-2015) number and location of jobs in two rather different metropolitan areas, we calibrate the model for each and validate it against actual data. Having found that the model performs well, we show how policy makers can use it to ask what-if questions regarding proposed policies to either attract businesses to specific locations or discourage them from locating in parts of the region.

Keywords: Regional urban systems, Anticipatory models, Network models, Regional employment location, Spatial dynamic location model, Anticipatory public policy scenarios, Complex urban systems
\end{abstract}

\section{Planning and public policy complexity challenges}

Planners and policy makers make decisions for the near or distant future of urban and regional systems embedded in natural systems. These systems are complex, and so are their numerous interlinkages. Typically, plans and policies in pursuit of specific objectives aim to outperform the do-nothing alternative. Owing to the numerous individuals and entities with diverging interests who make simultaneous and sequential decisions within these systems, as well as to the dynamics of the natural and social environments, joint outcomes of decisions and their spatial and other effects are difficult to predict.

The effects of alternative interventions and of nonintervention are seldom sufficiently knowable for comparisons and selection of preferred alternatives. Worse yet, at times planners and decision makers paint a desirable future state for a city or region (a

(C) The Author(s). 2019 Open Access This article is distributed under the terms of the Creative Commons Attribution 4.0 International License (http://creativecommons.org/licenses/by/4.0/), which permits unrestricted use, distribution, and reproduction in any medium, provided you give appropriate credit to the original author(s) and the source, provide a link to the Creative Commons license, and indicate if changes were made. 
normative scenario, Amer et al. 2013) with a horizon of 20 or more years, and then seek to identify the decisions that will lead to this target. In the context of complex systems in constant flux, this approach has a rather small likelihood of success. Not only is the normative scenario described in current terms-needs, technologies, constraints which may no longer have currency by the target year-but successfully reaching the target is also contingent on specific futures and therefore non-robust if these favorable conditions fail to materialize (e.g. Kaufman 2012, Simmie \& Martin 2010). Instead, the longer the horizon for which we plan, the more important it is to make robust decision that remain wise for a wide range of possible futures (e.g., Chakraborty et al. 2011; Kaufman et al. 2018).

Even when we have causal models of the complex reality for which we plan, they are imperfect at best, and they require taking into account numerous variables for which we have incomplete or incompatible data or have to use imperfect proxies. ${ }^{1}$ The prediction errors accumulate quickly. The quality of predictions diminishes rapidly with the length of the chosen planning horizon. However, the consequences of implemented plans and policies can have long-lasting and at times irreversible effects on cities and regions, not all of them as intended. Therefore, decision makers search for ways to reduce uncertainty and get a handle on future possibilities, in order to increase the effectiveness of their decisions and reduce unwanted side effects to the extent possible. One approach consists of anticipating a range of possible futures-descriptive scenarios-regarding specific features of interest, and pitting proposed plans or policies against this range to explore desirable effects and their robustness, as well as discover predictable surprises (Bazerman and Watkins 2004). The use of anticipatory scenarios as an approach for contending with complexity and uncertainty, although not of recent vintage (e.g. Schoemaker 1991), is gaining currency in the planning and policy fields (e.g., Godet 2000, Chakraborty 2010, Broitman and Czamanski 2012, Chakraborty and McMillan 2015, Vervoort \& Gupta 2018).

While the complexity of social-ecological systems seems to challenge our ability to produce the predictions necessary for making planning and policy decisions that yield the results sought, it can be of assistance for some specific purposes as we will show in this article. This requires us to switch from a research perspective, which we usually adopt, to that of a decision maker. In the quest to understand systems a researcher will seek causal linkages among numerous variables, at times in the absence of a guiding theory, in order to describe as accurately as possible how they affect the systems' states in time. This approach does not capture emergent phenomena, which are characteristic of complex systems (e.g. Klügl and Bazzan 2012; Beaverstock et al. 2002; Kriegler et al. 2012). Measurement and model specification errors accumulate rapidly, so beyond a short horizon the predictions are no better than no information at all. In contrast, decision makers are less concerned with systems' descriptions, except in so far as they enable assessment of decision consequences with reasonable accuracy to increase the likelihood of the desired outcomes while reducing the risk of unexpected consequences. Decision makers usually lack the time necessary to "get it right" or the resources needed to collect and process the data for all the variables researchers would consider

\footnotetext{
${ }^{1}$ Some proxies have been utilized so extensively in the past that they have acquired control variables status and are included in models without much theoretical backing.
} 
descriptively correct. They may be satisfied with models that provide information supporting robust decisions when needed, and at an affordable cost. The very complexity of the systems for which we plan may enable the generation of such models for certain decision problems.

In this article, we present a model of employment location in a regional space. This model is in a growing stream of efforts to create means for analyzing the dynamics of cities and regions, which combine urban economics and statistical physics tools (Barthelemy 2016). Decision makers can use this model to anticipate and explore ranges of spatial consequences of policies that affect the distribution of employment among a region's cities. It is parsimonious, requiring the estimation of only four parameters by using the first 2 years of employment time series accessible in the public domain. It takes advantage of a characteristic of complex systems: at one level of analysis we may need many variables to describe interrelated behaviors and outcomes, while at a higher level patterns emerge. These patterns allow us to engage in anticipation (Fuerth 2009; Fuerth and Faber 2012).

We begin by describing the model. Then we apply the model to two United States (U.S.) metropolitan economic regions that are quite different along several dimensions affecting employment dynamics. Using employment data from 2002 to 2015, we predict employment location in the regional space in time and compare results to the actual data, to assess the model's capability and its level of sensitivity to regional characteristics. Then we describe how to use the model to generate policy scenarios and explore spatial consequences on regional employment. We conclude with some ideas for practical applications of the model to planning and policy decisions, and for further model developments.

\section{Comparative analysis of two metropolitan areas}

We focus here on economic regions (Porter 2003) to model and explore how employment shifts in time among municipalities. We selected two Combined Statistical Areas (CSAs) as proxies $^{2}$ for two economic regions that differ along some characteristics which can be expected to affect dynamics of employment distribution in time.

The first region is the Dallas-Fort Worth Combined Statistical Area in Northeastern Texas (DFW), with 358 municipalities. The second is the Cleveland-Akron-Elyria Combined Statistical Area in Northeast Ohio (NEO), with 241 municipalities (Fig. 1). DFW has been deemed a "US economic powerhouse" (Kiersz 2018) and is ranked 7th of 40 regions in terms of job growth. It is attractive to people and businesses. NEO is considered a "legacy" region. Legacy cities and regions are "older, industrial urban areas that have experienced significant population and job loss, resulting in high residential vacancy and diminished service capacity and resources." (The Legacy Cities Partnership 2012). For example, while in the 1950 Census the city of Cleveland had a population

\footnotetext{
${ }^{2}$ Although (according to Porter 2003), economic regions are more stable over time than the Combined Statistical Areas, our data are for the latter. CSAs consist of combinations of adjacent metropolitan and micropolitan statistical areas with economic or social linkages. Economic linkage is measured by an employment interchange measure (i.e., the sum of the percentage of workers living in the smaller entity who work in the larger entity, and the percentage of workers in the smaller entity who reside in the larger entity). https://www.census.gov/programs-surveys/metromicro/about/glossary.html accessed March 25, 2019. The CSAs in our study are comprised of counties (we excluded Bryan County, Oklahoma, from the DFW CSA because state policies would not apply to a county in a neighboring state).
} 


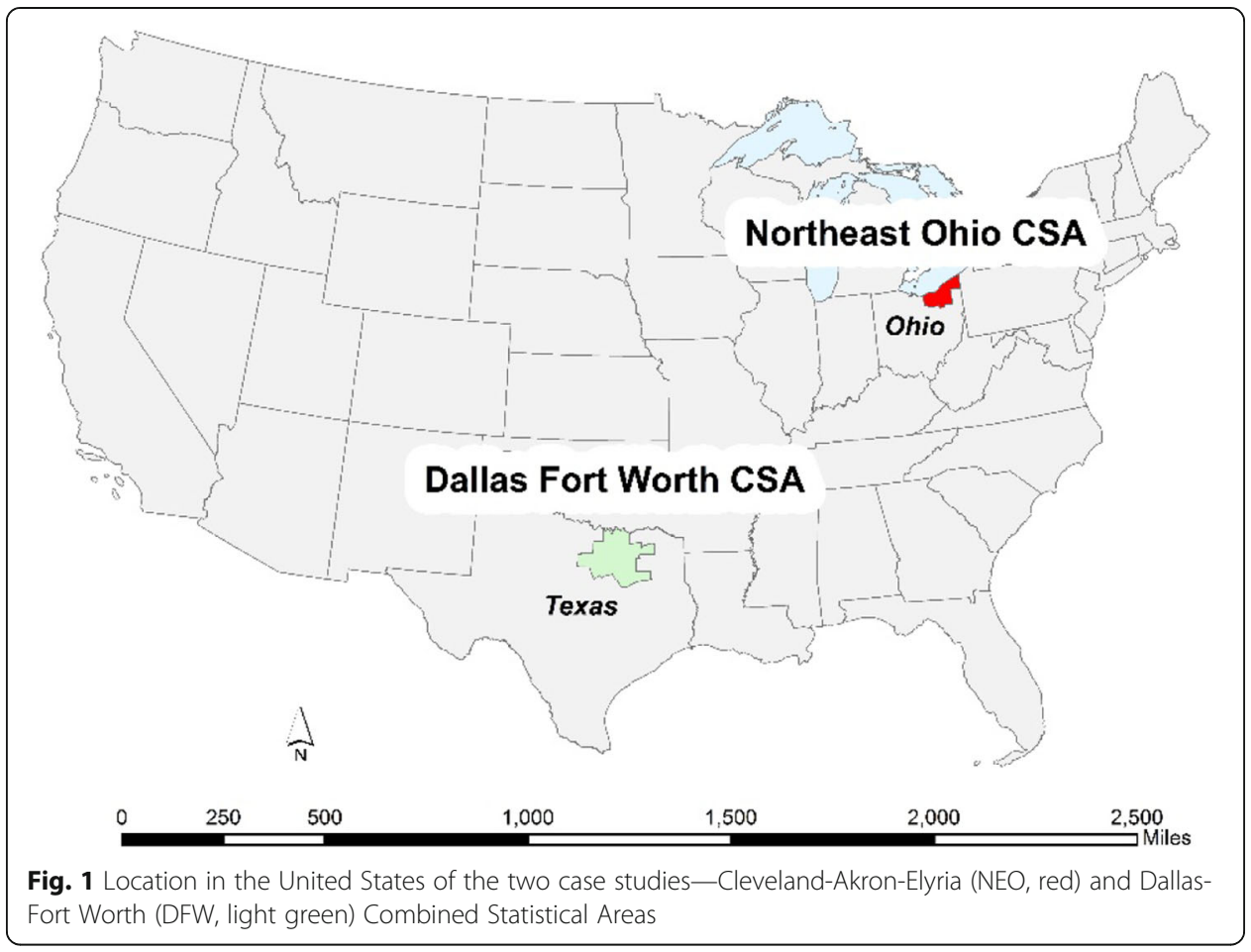

close to 915,000, by the 2010 Census it had declined to less than 400,000. NEO's Akron, Elyria and Mentor are also older industrial cities in decline over the past 50 or more years.

Table 1 captures some of the differences between DFW and NEO. For example, in 2015 (the last year of our data set) NEO had two thirds of the number of DFW's municipalities occupying a third of the DFW area, $40 \%$ of DFW's number of jobs, and 38\% of its population. The DFW region is relatively young, with population and employment located in two dominant cities much larger than the 356 smaller municipalities. In contrast, NEO's 241 municipalities have several large cities, and a set of other municipalities that bridge in size between the largest and the smallest. DFW employment grew by almost 30\% from 2002 to 2015, while NEO's employment growth during the same period was approximately ten times lower than in DFW, at about 3\%.

Figure 2 shows the change in employment in the municipalities of our two study regions between 2002 and 2015. The two maps of employment change bring out the difference between the growing DFW region and the stagnant-to-declining NEO region. DFW shows few patches of employment decline over the study period, coupled with intense economic activity in the region's center, around the two main cities. In

Table 1 Basic characteristics of the two study regions

\begin{tabular}{lll}
\hline Region Characteristics (2015) & Dallas-Fort Worth & Northeast Ohio \\
\hline Population & $7,499,272$ & $2,867,104$ \\
Number of municipalities & 358 & 241 \\
Area (sq. miles) & 16,222 & 3660 \\
Employment & $3,481,922$ & $1,364,568$ \\
\% change in employment, 2002-2015 & 29.7 & 3.1 \\
\hline
\end{tabular}



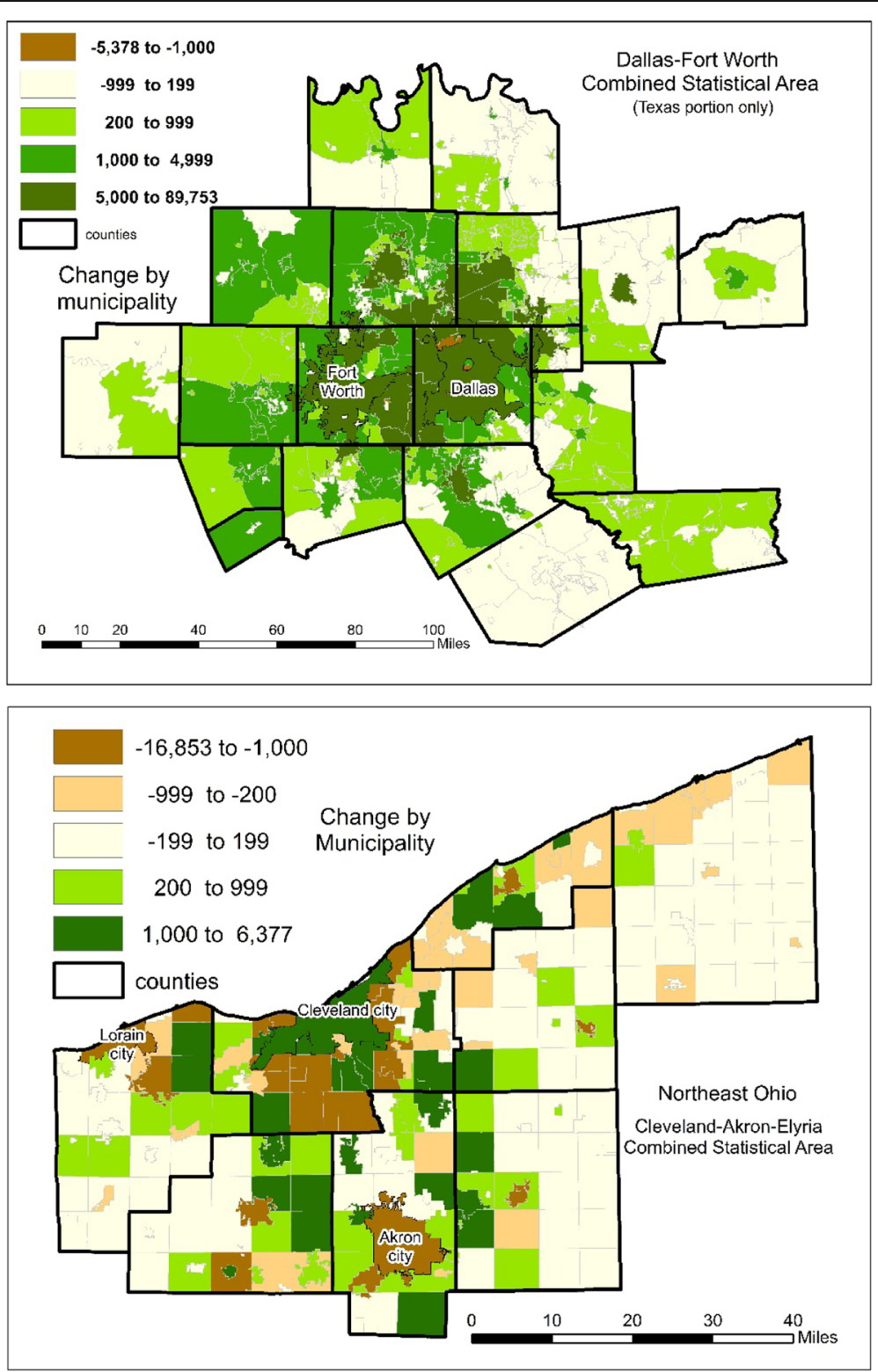

Fig. 2 Actual change in employment between 2002 and 2015 in DFW and NEO

contrast, although Cleveland saw some growth, NEO's other large cities show loss of employment. Note that the growth and decline ranges differ between the two maps: for example, the highest employment growth range (dark green) in DFW is between 5000 and 90,000 jobs, while the highest growth (dark green) in NEO is between 1000 and 6500 jobs. The largest decline is in a much lower range for DFW than for NEO. The city of Akron lost almost 17,000 jobs (15\%) in our study period.

To represent the qualitative difference among the two regions, we have computed the respective Shannon entropies (eq. 6 below) of their spatial employment distributions from 2002 to 2015 (Fig. 3). The higher the entropy value, the more distributed/graduated the regional structure is between large and small cities, which is the case for NEO, 


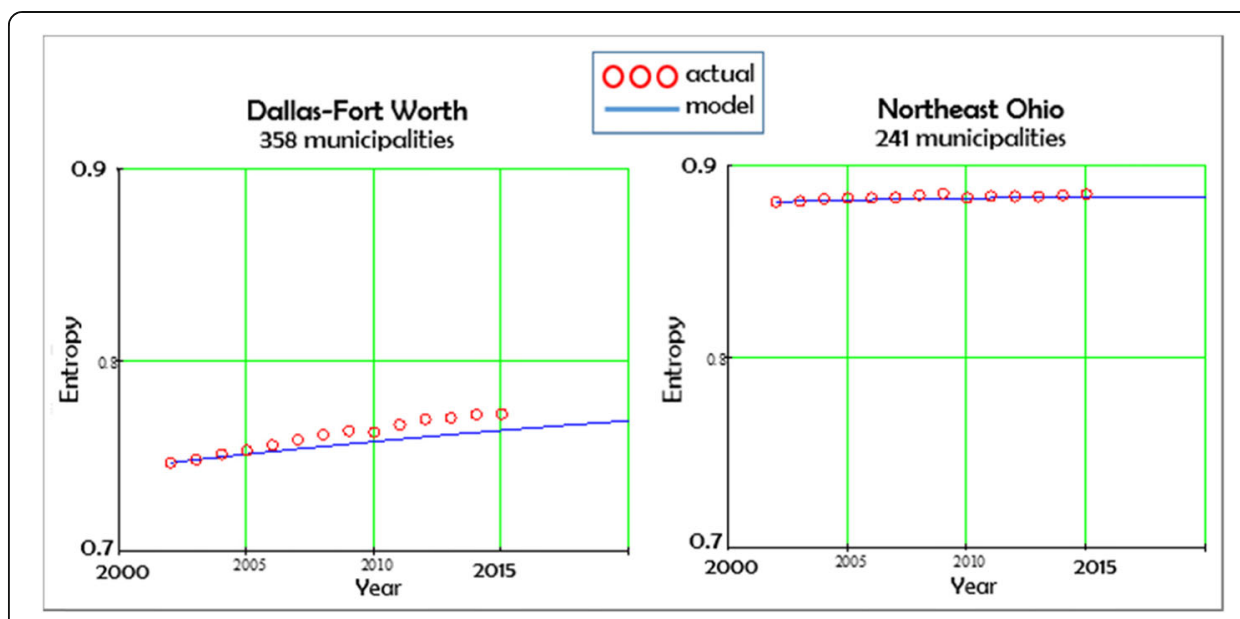

Fig. 3 Entropy of the regional spatial employment distribution for Dallas-Fort Worth and Northeast Ohio, 2002-2015

where the entropy hovers close to 0.9 for the entire time period considered. The lower the entropy, as for DFW, the more "polarized" the regional space-with two large cities and many small cities. The DFW entropy does not exceed 0.8 for the study period.

By being very different both in geographic location within the U.S. and in terms of their economies, the two regions we selected to compare offer the possibility of testing whether the model we propose can perform well for very different metropolitan economies. We expected the model to perform better for the NEO region, where change in time is rather slow, compared to the DFW region.

Whether in slow-growing regions such as NEO, or in rapid-growth regions, such as the DFW, municipalities compete for economic advantage in attracting industries and businesses. Though each locality can enact policies and regulations to this end, they are not independent in their region: when some places prosper, some others react with growth or decline. Decision makers need the ability to anticipate consequences on other places in a region when, for example, they use policies such as tax instruments to attract businesses to a location or set aside undeveloped land for conservation purposes. This requires the ability to capture region-wide interactions among municipalities following a policy intervention.

The model uses employment data by municipality, which we obtained from the publicly accessible Longitudinal Employer-Household Dynamics (Unites States Census Bureau). ${ }^{3}$ To capture the consequences of implementing a policy in one city on the rest of the region, the model needs the Euclidean distances between each pair of municipalities. ${ }^{4}$ Kumar et al. (2007) applied this model to biennial data on the spatial distribution of businesses in the Northeast Ohio region (1987-2000). Here we apply the model to the annual spatial distribution of number of jobs in both the Dallas-Forth Worth region and the North East Ohio regions, from 2002 to 2015.

\footnotetext{
${ }^{3}$ Block-level estimates of employment were aggregated to the municipality level.

${ }^{4}$ The Euclidean distance between the municipalities' centroids was calculated by means of Geographic Information Systems (GIS) software, using an Ohio State Plane North, NAD 83 projection, which produces relatively accurate distances at the scale of our analysis (the Ohio Department of Transportation and the Ohio Department of Natural Resources also use this projection).
} 


\section{The model}

We consider a region's localities as nodes in a network, with spatial interactions among the nodes. We use a parsimonious network model to anticipate the distribution of jobs among the different localities inside an economic region. We consider for each locality its proportion of the total number of jobs in the region (which does not restrict the regional total from one year to the next). The model is based on a dynamic rule (Krugman 1996) which captured how new spatial configurations emerge from a current spatial configuration through interactions among localities in a region.

In Krugman's model, given the interactions among a region's host localities, the emergence of employment centers is accounted for through self-organization. Kumar et al. (2007) discretized Krugman's model to enable its use with regional employment data. The rule underlying this model assumes that any location in a region exerts either an agglomerating force of attraction for businesses, or a dispersion force that repels them. The forces any location (municipality) x exerts on employment, and therefore the extent to which it can attract jobs, depend on this location's market potential relative to other places in the region. In the discretized version, the market potential of any location $\mathrm{x}$ at time $\mathrm{t}$ is:

$$
P_{t, x}=\sum_{y} q_{x, y} n_{t, y}
$$

where $n_{t, y}$ is the fraction of the total employment in a region at locations $y$, at time $t$. Thus, at any time $t$ the region's spatial sum of the densities $n_{t, x}$ equals unity:

$$
\sum_{x} n_{t, x}=1
$$

The matrix of interactions between any two locations $\mathrm{x}$ and $\mathrm{y}$ is:

$$
q_{x, y}=A \exp \left(-\frac{|x-y|}{D_{a}}\right)-B \exp \left(-\frac{|x-y|}{D_{b}}\right)
$$

where $|x-y|$ is the Euclidean distance between the centroids of municipalities $x$ and $y$. Parameter A represents the strength of the agglomeration force and parameter B represents the strength of the dispersion force. They are dimensionless. $D_{a}$ and $D_{b}$ are the ranges of these interactions. These parameters, as well as all distances between localities (initially measured in feet), are expressed in (dimensionless) units of the largest inter-localities distance. A, B, $D_{a}$ and $D_{b}$ are the four parameters to be estimated from the data. The spatial average of the market potential at a specific time $\mathrm{t}-$ as defined in eq. 1 -is:

$$
\overline{P_{t}}=\sum_{x} \sum_{y} q_{x, y} n_{t, x} n_{t, y}
$$

This average market potential is, according to Krugman, the term of comparison for establishing whether a municipality will attract or repel employment. Employment gradually gravitates towards locations considered relatively attractive, i.e. their market potential is above average: $P_{t, x}>\overline{P_{t}}$. Similarly, employment tends to move away from locations with below-average market potential: $P_{t, x}<\overline{P_{t}}$. The discretized version of the Krugman model's the dynamic equation representing how employment moves across the region from one time period to another is:

$$
n_{t+1, x}-n_{t, x}=\left(P_{t, x}-\overline{P_{t}}\right) n_{t, x}
$$


where the time interval is 1 year. The model preserves the spatial sum of the densities $\mathrm{n}_{\mathrm{t}, \mathrm{x}}$ (eq. 2) at any time $\mathrm{t}$.

The data necessary for estimating the model's four parameters $A, B, D_{a}$ and $D_{b}$, consists of the location and employment numbers for a region's municipalities in two consecutive time periods. We consider the actual employment number in each locality of the region in the first time period to be the initial distribution of employment in the regional space. We run eq. 5 with these initial data and a trial set of parameter values to obtain the employment distribution in the following time period, and we compute its actual and model values of the Shannon entropy (Kumar et al. 2007):

$$
S=-\sum_{j} n_{j} \ln \left(\frac{n_{j}}{A_{j}} A_{\text {min }}\right)
$$

where $n_{j}$ is the fraction of all jobs in locality $j, A_{j}$ is the area of locality $j$ and $A_{\min }$ is the smallest locality area. This formula accounts for differences in localities' areas (Kumar et al. 2007). The entropies reported in Fig. 3 are normalized by the maximum value, so they vary on a scale from 0 to 1 .

We search iteratively to find the "best" set of parameter values, in the sense that they correspond to the smallest difference between the actual and simulated entropies in the second time period. Having obtained these "best" parameter values, we use them to predict the proportion of firms at each location in the region for other time periods (eq. 5).

\section{Model results for the DFW and NEO economic regions}

We estimated the model parameter values for each of the two regions (Table 1), using 2002 and 2003 employment data. Note that they are different for the two regions: A and B values (representing the municipalities' strength of the agglomeration and rejection forces) are larger for NEO, while $\mathrm{D}_{\mathrm{a}}$ and $\mathrm{D}_{\mathrm{b}}$ values (representing the ranges of the inter-municipality interactions) are higher for DFW (Table 2).

In general, each region will have its specific parameter values. Figure 4 shows the average market potential for each of the two regions in time (2002-2015). Note that the average market potential goes up monotonically over time. This is consequence of this model's dynamics, which increase the shares of localities having an above-average market potential, while diminishing the shares of localities with below-average market potential. From 2002 to 2015, the average market potentials of both regions grew at an annual rate of about 3\%, slightly higher for DFW than for NEO. The absolute value of the average potential market for DFW region is smaller than for NEO region probably due to NEO's more uniform distribution of employment centers compared to DFW, which has a higher number of smaller localities with larger distances among them.

Table 2 Model parameter values for the DFW and NEO regions ( $A$ and $B$ are dimensionless and $D_{a}$ and $D_{b}$ are expressed in units of the largest inter-locality distance: DFW: $9.735 * 10^{5} \mathrm{ft}$; NEO: $5.647 *$ $\left.10^{5} \mathrm{ft}\right)$

\begin{tabular}{lllll}
\hline Parameter Region & $\mathrm{A}$ & $\mathrm{B}$ & $\mathrm{D}_{\mathrm{a}}$ & $\mathrm{D}_{\mathrm{b}}$ \\
\hline Dallas-Fort Worth & 0.333 & 0.25 & 1 & 0.917 \\
Northeast Ohio & 0.667 & 0.5 & 0.583 & 0.417 \\
\hline
\end{tabular}



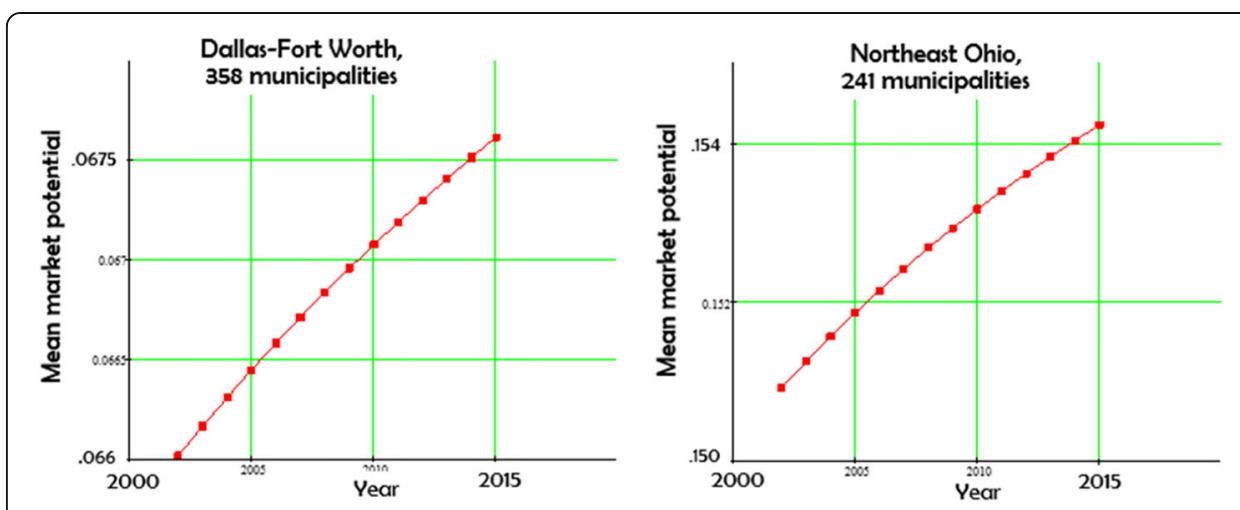

Fig. 4 Average market potential in time, by region

NEO is an older, multi-centric region with several large cities, whereas DFW is younger, with only a couple of large employment centers.

Using the parameter estimates obtained with 2002 and 2003 data and eq. 5, we generated for each region the share of the total regional employment in each municipality up to year 2020. To compare the predictions to actual (known) values and obtain a measure of the model's goodness of fit in both cases, we computed the correlations between actual and predicted values for each municipality in each region (Fig. 5) for years $2003-2015 .^{5}$ The 2002 correlation is $100 \%$ because we used 2002 data to estimate parameters so actual and predicted values are identical. In general, the quality of prediction typically declines with time, often rather rapidly. The prediction precision did indeed decline for both regions in our network model too. However, surprisingly, the decline was relatively small: in the last year (2015) for which actual data were available for both regions, the correlation between actual and predicted values for the DFW region was higher than .996, while for NEO it exceeded 985 .

Note in both regions some unusual behavior at around the same time (Fig. 5). For DFW, there is a (relatively) sharp drop in the correlation value in 2010, and a (relatively) smaller drop for NEO. Although we have no direct means to verify, we conjecture that the small "turbulence" in the two correlation series reflects lagged reactions to

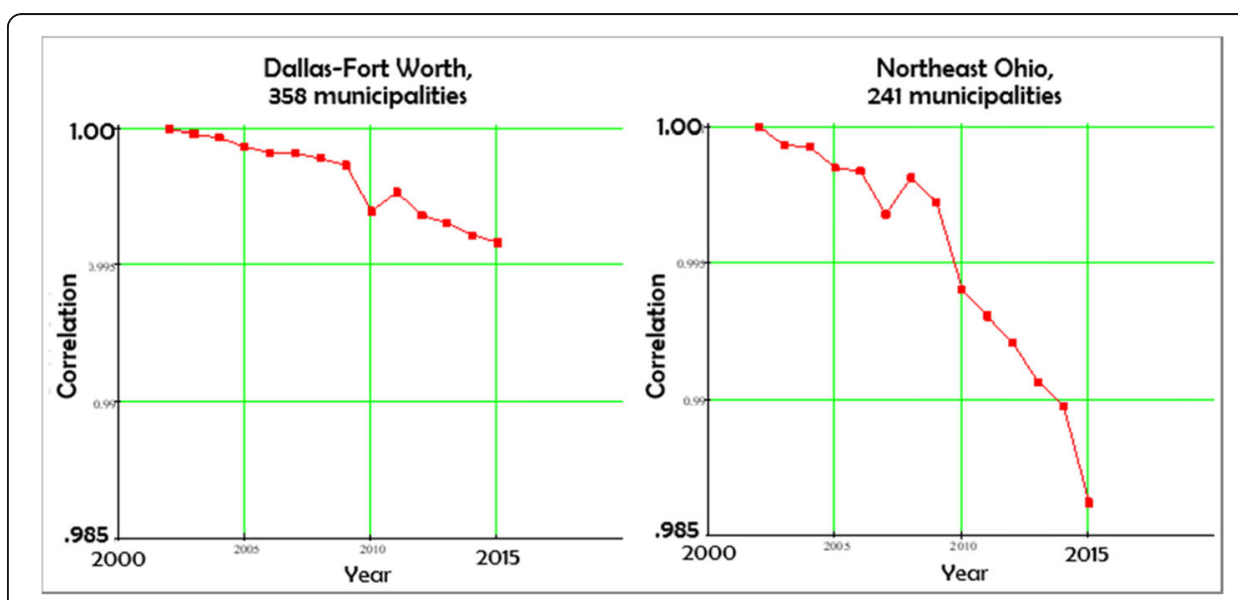

Fig. 5 Correlations between actual and predicted employment by municipality, Dallas-Fort Worth and Northeast Ohio regions, 2002-2015 
the 2008 economic downturn in the United States. ${ }^{6}$ Nevertheless, the correlation values remained high for both regions even after the economic shock. The 2008-2010 correlation values suggest that even this high-performing model cannot be relied upon to anticipate an economic downturn of 2008 magnitude and national scope. On the other hand, during the 15-year time series there were other, potentially destabilizing events of sub-national scale in each region whose consequences on regional employment the model seems to have absorbed while maintaining the quality of prediction.

What of model predictions for specific municipalities? Figures 6 and 7 show examples of such predictions for two large and two small cities in each region. In DFW's case (Fig. 6) there is a negligible difference between actual and predicted values of employment. The two large cities in particular show no sign of a discrepancy even for the 2 years following the 2008 economic downturn. For Grand Prairie, a small town, the model overestimated the employment even before 2008. Lewisville, another small town, shows very small deviations from the model after 2008. The cumulative effect of the numerous small towns such as Grand Prairie and Lewisville are likely responsible for the 2008 effect observed in Fig. 5.

The same small-town effects can be observed for the NEO region's cities of Strongsville and Westlake, with the former's actual employment matching the model's predictions while the latter shows some 2008 consequences. The pattern for the large cities of Cleveland and Akron is different from the DFW region. While Akron's actual and predicted values track each other quite closely, in 2015 the model underestimated Cleveland's actual economic performance by $5 \%$ of the total regional employment. ${ }^{7}$ This means, in the language of our model, that Cleveland had a larger actual market potential than predicted, especially starting in 2010. One possible reason for this city's over-performance is that after the 2008 economic downturn policies were implemented to counter it and boost the city's ability to attract employment. ${ }^{8}$ Consequently, while employment did not grow, it retained its share of the total regional employment, losing less than it might have in the absence of those policies. Since our model captures the entire regional space, Cleveland's policy-supported stability may have come at the expense of other cities in the region (per eq. 2). In particular, we note the pattern of

\footnotetext{
${ }^{5}$ Note that we have also compared our model results to a simple trend model predicting employment separately for each city in both the DFW and NEO regions. In both cases, the model results, with only 4 parameters, performed better than year-to-year trends with numerous parameters (for the hundreds of localities in each region). Moreover, our model has an economic rationale, while trends lack it and cannot be used to generate anticipatory policy scenarios, which is our objective.

${ }^{6}$ We first had access to biennial data for the NEO region (Kaufman et al. 2018). The biennial correlations for NEO corresponding to those displayed in Figure 5 declined monotonously, showing no reaction to the 2008 economic downturn. This may mean the NEO region quickly resumed its behavior after the 2008 shock to the economy.

${ }^{7}$ Note that in all cases the range of discrepancies between actual and predicted values is quite narrow (Figures 6 and 7). Therefore, even when the model over- or underestimates actual values of the employment shares out of the regional total, the differences remain extremely small (the largest in 1 year, for Cleveland, is less than .05.)

${ }^{8}$ This conjecture is supported for example, by a contemporary article in DiversityInc: "A recent Brookings Institute report [https://www.brookings.edu/wp-content/uploads/2016/07/2010_03_great_lakes_monitor-1. pdfaccessed Apr 102,019] found Cleveland is on the road to resurgence, ranking 10th among 50 U.S. metro areas. That's because of its diversification from a primarily industrial base to "new economy" sectors, such as healthcare, biosciences and high-tech industries. Based on annual employment growth and per-capita income, the study found Cleveland's income jumped 4.1\% from 2009 to 2010 compared with pre-recession years (1993-2007)." https://www.diversityinc.com/diversity-drives-clevelands-economic-recovery/, Accessed Apr 10, 2019).
} 


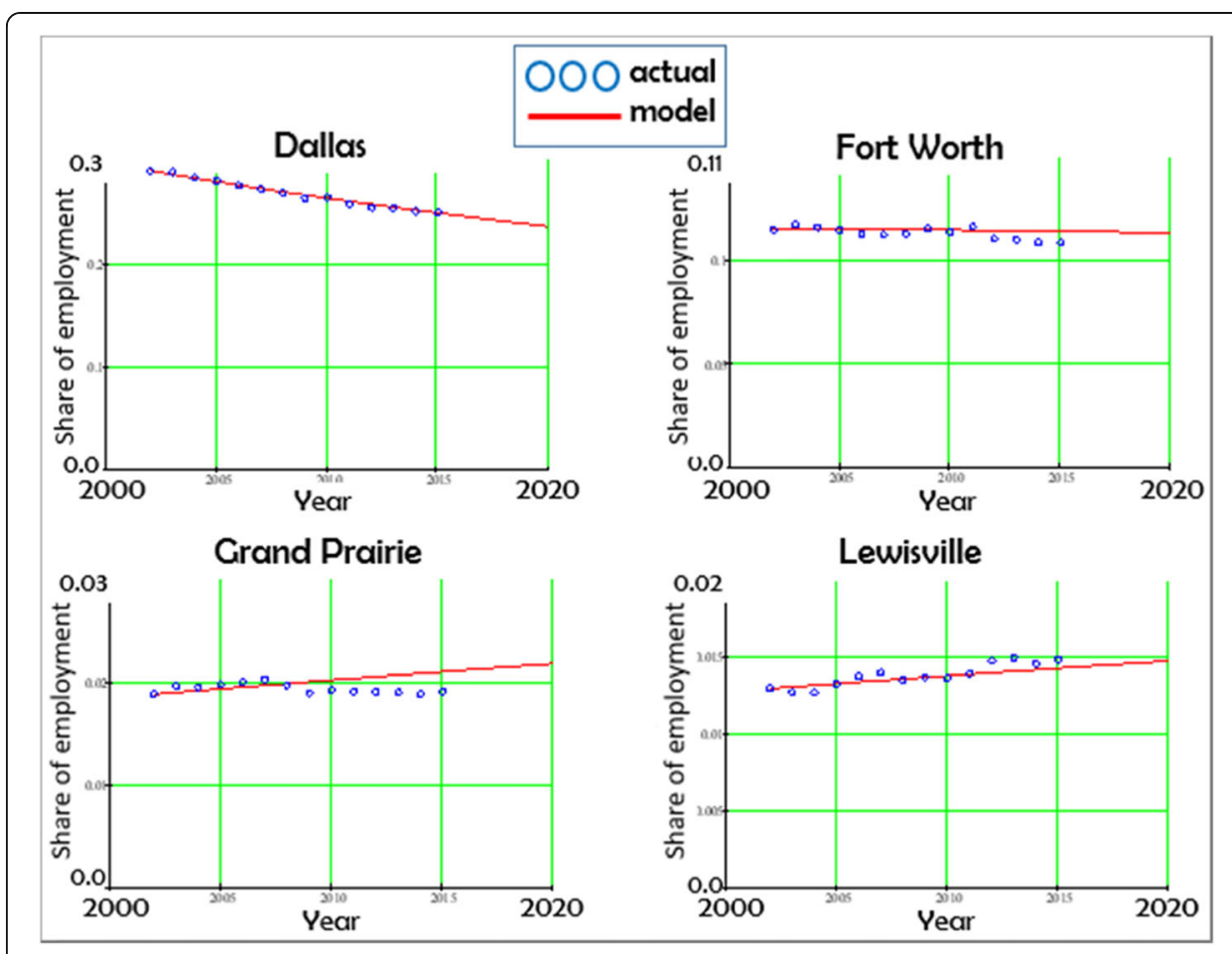

Fig. 6 Shares of total regional employment in 4 Dallas-Fort Worth cities, 2002-2020

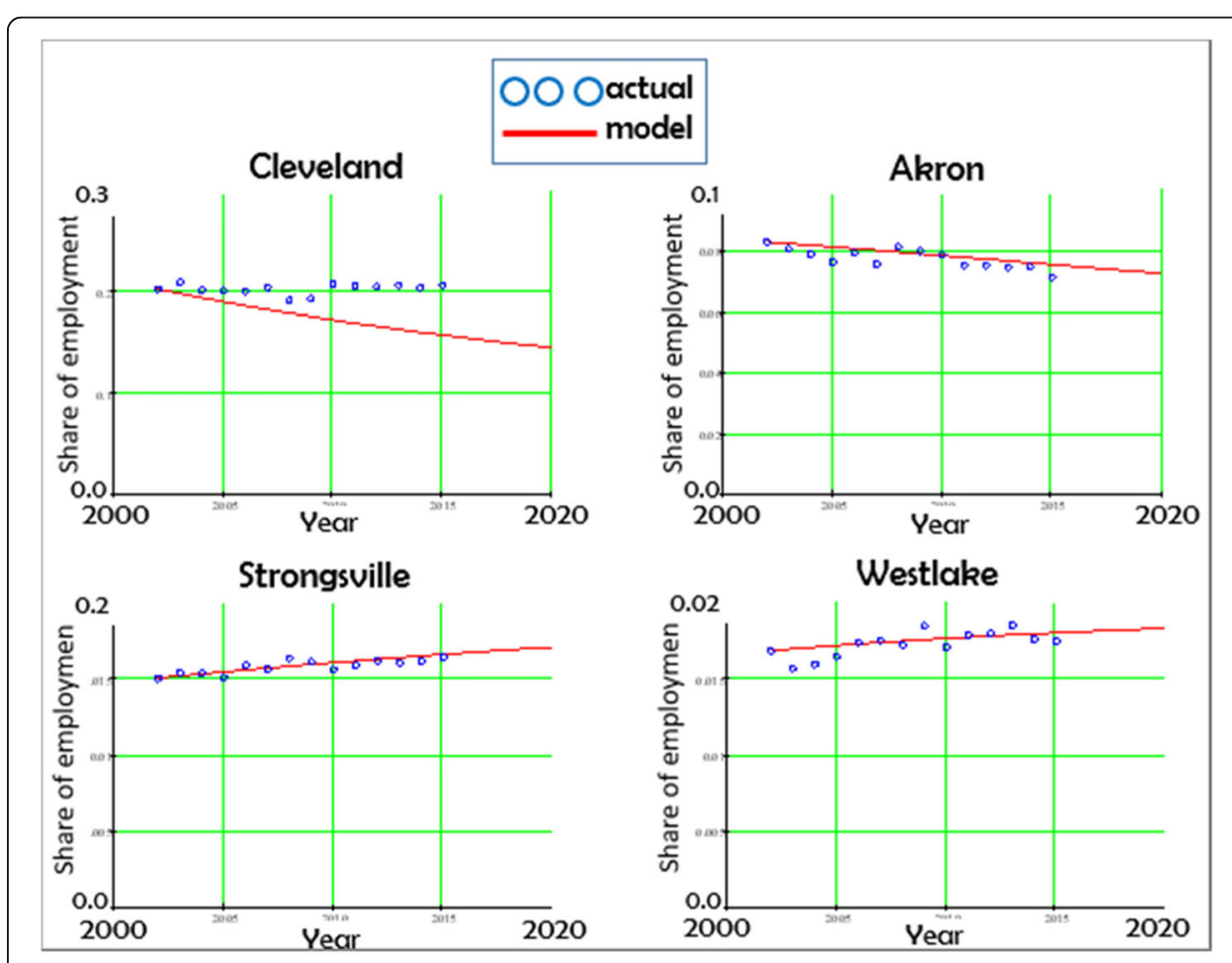

Fig. 7 Shares of total regional employment in 4 Northeast Ohio cities, 2002-2020 
relative losses among the city's inner-ring suburbs, as well as for its main large-city competitor in the region, the city of Akron.

\section{Using the model to test policy decisions}

We selected for this study two very different economic regions in order to explore which differences, if any, affect model performance. We expected the model to perform better for the older, slow-changing NEO legacy region. We also expected the model to be "surprised" more often by the reality of the intensely active and economically growing DFW region. Our hypothesis was not supported: the correlations between actual and predicted values (Fig. 5) were higher for DFW, meaning that the model performed slightly better for that region. However, the high correlation values in both regions from 2002 to 2015 give us a measure of confidence in using the model to generate employment consequences for policy scenarios for these two regions for horizons of at least 10 to 15 years, comparable to the length of our time series. For exploratory purposes, we might even extend the horizon.

Anticipatory scenarios of complex systems such as economic regions can assist decision makers in testing whether a policy under consideration could be expected to attain its objectives. No less important is the capability to discover other effects of the policy, whether desirable or not. This is especially difficult to accomplish in the presence of complexity. Decision makers are apt to be unpleasantly surprised especially by irreversible consequences. Although narrowly focused on the distribution of employment within regions, our model takes into account the dynamics of an entire region and can therefore help test questions such as: what would happen to the city of Dallas' market potential if a policy were to encourage development in some of the DFW region's smaller municipalities? What could happen to the region if the two largest cities resolved to compete for employment by offering tax abatements to certain industries? For the NEO region, we might ask what happens to small municipalities when the region's legacy cities receive a tax policy boost for a limited time. We could also investigate how land conservation decisions affect employment in the places directly affected by restrictions.

Kaufman et al. (2018) explored three policies that either directly aimed at affecting the market potential of some NEO's cities or could impact market potential as a result of land conservation decisions. We compared the resulting anticipatory scenarios to the known "do-nothing" alternative represented by the actual data. Besides watching for regional effects of localized policies, we wondered how lasting the policy effect would be (Fig. $8^{9}$ ).

Note that even a "do-nothing" alternative is not really "do-nothing" in the sense that individuals, organizations and public agencies make decisions all the time that likely affect the cities' market potential. For instance, improving education, roads or recreation options in a city are all apt to improve that city's appeal to businesses. In fact, social-ecological systems are complex not least because of the emergent outcomes stemming from the activities of all entities that combine in unpredictable ways. The

${ }^{9}$ The study by Kaufman et al. (2018) the number of firms rather than number of jobs in order to update and compare results to the earlier Kumar et al. (2007) study. Outcomes using the employment data differ minimally from those using number of firms. 


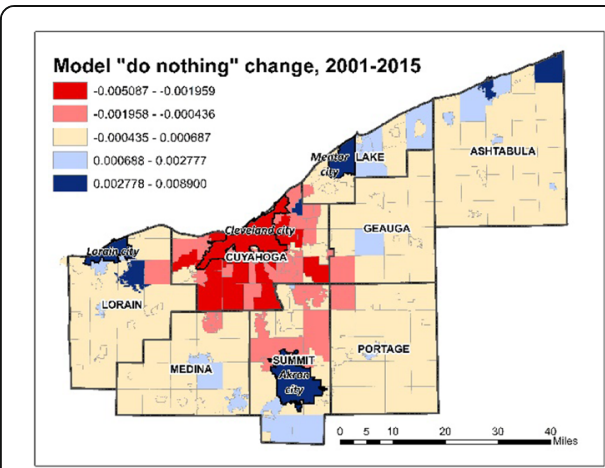

a.

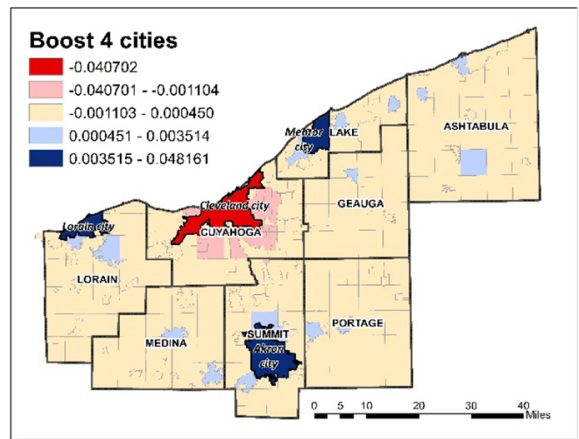

c.

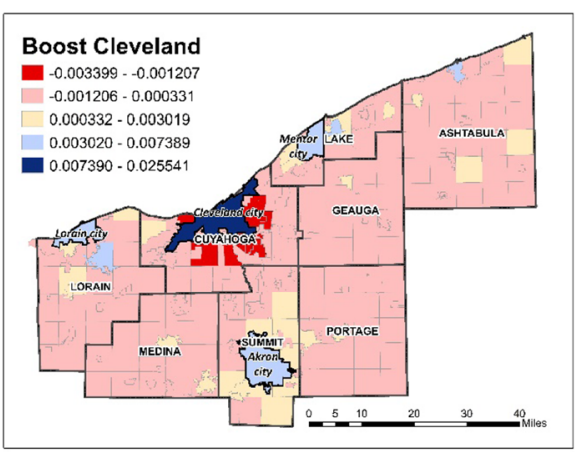

b.

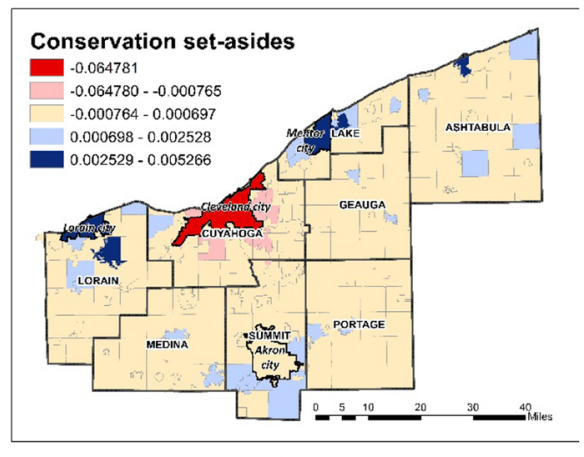

d.

Fig. 8 Regional employment location-change from 2001 to 2015 in the "do-nothing" and in 3 anticipatory scenarios for the NEO region: a. "do-nothing"; b. boost Cleveland in 4 consecutive time periods; c. boost 4 legacy cities (including Cleveland) in 4 consecutive time periods; $\mathbf{d}$. conservation set-asides along the Cuyahoga National Park

scenarios are helpful in highlighting effects of policy changes that meaningfully alter business location incentives across the region.

Figure 8. a. displays the change in economic activity in the NEO region from 2001 to 2015 in the absence of a policy intervention regarding employment location. In the first NEO policy scenario (Kaufman et al. 2018), we assumed that Cleveland's ability to attract businesses from 2001 to $2007^{10}$ was enhanced through taxation instruments. As a result, its share of the total regional employment rose by .04 every year. Per eq. 2 , this increase came at the expense of a total decrease of .04 among the other municipalities. The model change from 2001 to 2015 (Fig. 8.b) should give pause to policy makers considering such a decision, in the sense that they were not easily foreseeable. ${ }^{11}$ First, when the incentives were discontinued, Cleveland returned to slow decline and gradually lost almost all its advantage. Second, some neighboring large cities in the region (Akron, Lorain) also attracted a higher proportion of the regional employment, with a

\footnotetext{
${ }^{10}$ Note that Kaufman et al. (2018) used biennial data.

${ }^{11}$ For all four scenarios in Figure 8, red and pink colors denote strong and moderate decreases in employment respectively in 2015, while dark, medium and light blue denote strong, moderate and low increases respectively.

${ }^{12} \mathrm{We}$ considered here the intra-regional competition for employment. However, it is possible to design policies that attract to a location specific industries from outside the region, such that the resulting regional impact on other municipalities is positive, rather than at their expense.
} 
lag. The large cities' advantage came at the expense of several small municipalities, which quickly lost their market potential and did not manage to recover it. By 2015 they "disappeared" in terms of employment. ${ }^{12}$

In the second NEO scenario (Fig. 8.c), each of four legacy cities in the regionCleveland, Akron, Lorain and Mentor-got a 0.1 boost in their shares of the regional employment from 2003 to 2007. This amounts to the same total withdrawal of 0.4 employment share from the rest of the region as in scenario 8.b. At the outset the targeted cities benefit from the policy, outperforming the "do-nothing" scenario, though Cleveland benefits the least. However, we see again that, as in Scenario 8.b, by 2015 Cleveland and Akron resume their "do-nothing" trajectories after the incentive policy is discontinued. The results among the small municipalities are mixed, with some declining and some disappearing as they lose some or all of their regional employment share.

The third NEO scenario is different, in that its effects on employment share, if any, are indirect. In this scenario, 14 municipalities along the Cuyahoga Valley National Park had their market potentials capped to the 2002 levels, to discourage additional development in those cities that might damage ecological assets (Fig. 8.d). By 2015, the consequence of this policy decision on other NEO places was not extensive and was dispersed throughout the region. In general, effects of capping of the market potential are likely to depend on the size of the localities involved. The larger a capped city, the larger the proportion of regional employment being redistributed to other places. Our model offers the possibility for decision makers to test such regional effects.

Should the employment location model be used to explore effects of specific policy decisions in a region, several actions are necessary. First, to increase anticipatory accuracy, the model's parameters have to be estimated using the two most recent time periods for which data are available. For our two cases, currently those years would be 2014 and 2015. Next, there needs to be sensitivity testing of the parameter estimates. We would seek a range for each of the four parameters for which the model results are not significantly different. Finally, we would generate answers to a set of "what if" questions by producing responses to ranges of policy decisions. For example, for the first NEO scenario, we might seek to identify the size of the tax incentives and the length of time necessary to apply it in order to obtain sustained growth in Cleveland. We may discover that the answer is not very different from the values we used in the first scenario (Fig. 8.b), or that sustaining employment growth through tax incentives is infeasible. Both answers are valuable to decision makers. A version of the second scenario (Fig. 8.c) could be used to explore strategic configurations of city candidates for tax incentives to obtain positive results across the region. Similarly, using a version of the conservation scenario (Fig. 8.d), we might seek the maximum amount of land conservation-and its location-that still leaves the region insignificantly affected in terms of employment.

\section{Conclusions}

The spatial network model yields predictions that are very close to the actual figures for two regions that are very different in their location, and in their physical and economic structures. This suggests the model has broad applicability, at least 
in the United States. We argue, however, that point predictions are not useful in informing public policy for complex systems such as economic regions. Instead, anticipation is a better approach. It requires incorporating into the model specific policy changes and deriving ranges of consequences the decision makers can use to explore whether their proposed policies are likely to accomplish what they seek, and whether they might have major undesirable consequences. We illustrated this anticipatory scenario approach for one of the regions. The approach can be used in participatory decision processes.

While the model is parsimonious and uses open-access data, it has several drawbacks. For researchers, the model does not offer a causal description of employment location dynamics. For decision makers, utilizing the model to explore various decisions requires some professional assistance and a level of trust, since they are unlikely to understand how the model generates answers to their questions. We have tested a 15year horizon over which the model yielded satisfactory results in two very different regional contexts; however, unless a longer time series becomes available, we cannot extend this anticipatory horizon. Note that it may be unwise to use such models for targets exceeding approximately 15 years. We argued that social-ecological systems such as regional economies are complex. Besides the many actors making decisions independent decisions, and external factors which also affect the systems' course in time, quickly developing technology can have sizeable systemic effects. New technologies have already altered production, communication, transportation and other regional processes that will change how employment locates in regions.

We continue to develop this line of inquiry in several directions. We will explore alternative distance measures (rather than the Euclidean) such as driving or temporal distances. To improve the model, we plan to apply it to other US regions, as well as to regions outside the US, to test its applicability to various economic scales and structures. Contingent on data availability, we may be able to apply the model to the entire United States. We will characterize the spatial networks and suppress some links-for example, among large metropolitan areas and small municipalities at great distances from the economic centers unlikely to affect each other significantly-to test whether such networks improve or degrade the model's performance. We will explore the possibility of taking into account interactions with other regions with similar dominant industries.

We intend to refine our scenario approach in several ways. We will design some scenarios relevant to the DFW region. We will also examine a broader set of policies that may directly or indirectly alter the employment distribution across regions. For example, we can explore how the transportation network configurations and their improvement impact regional employment location. We also plan to study the impacts on employment location of different industry mixes in economic regions.

\footnotetext{
Abbreviations

CSA: Combined Statistical Area; DFW: Dallas-Fort Worth CSA; LEHD: Longitudinal Employer-Household Dynamics; LODES: Origin-Destination Employment Statistics; NEO: Cleveland-Akron-Elyria CSA; U.S.: United States
} 
questions and scenarios, interpreted the results in policy terms, and drafted the manuscript. MK formulated and operated the network model, participated in the interpretation of results for the two study areas, and helped to draft the manuscript. MS was responsible for data acquisition and management, the GIS mapping, scenario formulation and analysis, and helped to draft the manuscript. Each author has participated sufficiently in the work to take public responsibility for appropriate portions of the content. All authors read and approved the final manuscript.

\section{Authors' information}

SK is a planner who specializes in planning and public policy decision processes and the mitigation of the conflicts they generate.

MK is a physicist who specializes in statistical physics, including its applications to sociophysics.

MS is a geographer and demographer who specializes in the use of Geographic Information Systems (GIS) to represent the spatial dimensions of planning and public policy issues.

\section{Funding}

This project received support from the Cleveland State University's Office of Sponsored Research.

\section{Availability of data and materials}

The datasets generated and/or analysed during the current study are available at:

- U.S. Census Bureau, Longitudinal Employer-Household Dynamics. https://lehd.ces.census.gov/, last visited on February

$27,2019$.

- The Longitudinal Employer-Household Dynamics (LEHD) program is part of the Center for Economic Studies at the U.S. Census Bureau. We collected:

- LEHD Origin-Destination Employment Statistics (LODES) [https://lehd.ces.census.gov/data/]

- Files used: WAC - Workplace Area Characteristic data, jobs are totaled by work census block, aggregated to census county subdivision and census place portions.

\section{Competing interests}

The authors declare that they have no competing interests.

\section{Author details}

'Department of Urban Studies, Levin College of Urban Affairs, Cleveland State University, 2121 Euclid Avenue, Cleveland, OH 44115, USA. ${ }^{2}$ Department of Physics, Cleveland State University, Cleveland, USA. ${ }^{3}$ Levin College of Urban Affairs, Cleveland State University, Cleveland, USA.

Received: 6 May 2019 Accepted: 10 September 2019

Published online: 13 November 2019

\section{References}

Amer M, Daim TU, Jetter A (2013) A review of scenario planning. Futures 46:23-40

Barthelemy M (2016) The structure and dynamics of cities. Cambridge University Press, Cambridge

Bazerman MH, Watkins M (2004) Predictable surprises: the disasters you should have seen coming, and how to prevent them. Harvard Business Press, Cambridge

Beaverstock JV, Doel MA, Hubbard PJ, Taylor PJ (2002) Attending to the world: competition, cooperation and connectivity in the World City network. Global networks 2(2):111-132

Broitman D, Czamanski D (2012) Polycentric urban dynamics--heterogeneous developers under certain planning restrictions. Journal of the Urban \& Regional Information Systems Association 24(1):25-33

Chakraborty A (2010) Scenario planning for effective regional governance: promises and limitations. State and Local Government Review 42(2):156-167. https://doi.org/10.1177/0160323X10377344

Chakraborty A, Kaza N, Knaap GJ, Deal B (2011) Robust plans and contingent plans: scenario planning for an uncertain world. J Am Plan Assoc 77(3):251-266. https://doi.org/10.1080/01944363.2011.582394

Chakraborty A, McMillan A (2015) Scenario planning for urban planners: toward a practitioner's guide. J Am Plan Assoc 81(1): 18-29. https://doi.org/10.1080/01944363.2015.1038576

Fuerth LS (2009) Foresight and anticipatory governance. Foresight 11(4):14-32

Fuerth LS \& Faber EM (2012) Anticipatory governance practical upgrades: equipping the executive branch to cope with increasing speed and complexity of major challenges. National Defense University Fort McNair DC, Institute For National Strategic Studies

Godet M (2000) The art of scenarios and strategic planning: tools and pitfalls. Technol Forecast Soc Chang 65(1):3-22

Kaufman S (2012) Complex systems, anticipation, and collaborative planning for resilience. In Goldstein B (ed) Resilient Organizations: Social Learning for Hazard Mitigation and Adaptation MIT press 61-98

Kaufman S, Kaufman M, Salling M (2018) Dynamic firm location network model with anticipatory scenarios for the Northeast Ohio region. Journal on Policy and Complex Systems 4(2):115-136

Kiersz A (2018) The economies of the 40 biggest US cities, ranked from worst to best. Business Insider, June 20. https://www. businessinsider.com/us-economy-by-metro-area-ranked-san-francisco-seattle-austin-2018-4

Klügl F, Bazzan A (2012) Agent-based modeling and simulation. Al Mag 33(3):29-29

Kriegler E, O'Neill BC, Hallegatte S, Kram T, Lempert RJ, Moss RH, Wilbanks T (2012) The need for and use of socio-economic scenarios for climate change analysis: a new approach based on shared socio-economic pathways. Glob Environ Chang 22(4):807-822

Krugman P (1996) The self-organizing economy. Blackwell, Cambridge MA

Kumar M, Bowen WM, Kaufman M (2007) Urban spatial pattern as self-organizing system: an empirical evaluation of firm location decisions in Cleveland-Akron PMSA, Ohio. Ann Reg Sci 41(2):297-314 
Porter M (2003) The economic performance of regions. Reg Stud 37(6-7):549-578 Def of economic regions

Schoemaker PJ (1991) When and how to use scenario planning: a heuristic approach with illustration. J Forecast 10(6): 549-556

Simmie J, Martin R (2010) The economic resilience of regions: towards an evolutionary approach. Camb J Reg Econ Soc 3(1): 27-43 Economies \& resilience

The Legacy Cities Partnership, (2012) http:// http://www.legacycities.org/.

U.S. Census Bureau, (n.d.) Longitudinal Employer-Household Dynamics. https://lehd.ces.census.gov/.

Vervoort J, Gupta A (2018) Anticipating climate futures in a 1.5 C era: the link between foresight and governance. Curr Opin

Environ Sustain 31:104-111 Anticipatory governance

\section{Publisher's Note}

Springer Nature remains neutral with regard to jurisdictional claims in published maps and institutional affiliations.

Submit your manuscript to a SpringerOpen ${ }^{\odot}$ journal and benefit from:

- Convenient online submission

Rigorous peer review

- Open access: articles freely available online

- High visibility within the field

- Retaining the copyright to your article

Submit your next manuscript at $\boldsymbol{\nabla}$ springeropen.com 